\title{
Protection of Petroleum Pipeline Carbon Steel Alloys with New Modified Core-Shell Magnetite Nanogel against Corrosion in Acidic Medium
}

\author{
Gamal A. El Mahdy, ${ }^{1,2,3}$ Ayman M. Atta, ${ }^{1,2,4}$ Amro K. F. Dyab, ${ }^{5}$ and Hamad A. Al-Lohedan ${ }^{1,2}$ \\ ${ }^{1}$ Chemistry Department, College of Science, King Saud University, P.O. Box 2455, Riyadh 11451, Saudi Arabia \\ ${ }^{2}$ Research Chair of Surfactant, Chemistry Department, College of Science, King Saud University, P.O. Box 2455, Riyadh 11451, \\ Saudi Arabia \\ ${ }^{3}$ Chemistry Department, Faculty of Science, Helwan University, Helwan, Egypt \\ ${ }^{4}$ Egyptian Petroleum Research Institute, Nasr City, Cairo 11727, Egypt \\ ${ }^{5}$ Chemistry Department, Faculty of Science, Minia University, Minia 61519, Egypt
}

Correspondence should be addressed to Gamal A. El Mahdy; gamalmah2000@yahoo.com

Received 22 August 2013; Revised 9 October 2013; Accepted 11 October 2013

Academic Editor: Ali Nokhodchi

\begin{abstract}
Copyright ( $) 2013$ Gamal A. El Mahdy et al. This is an open access article distributed under the Creative Commons Attribution License, which permits unrestricted use, distribution, and reproduction in any medium, provided the original work is properly cited.

New method was used to prepare magnetite nanoparticle based on reduction of Fe(III) ions with potassium iodide to produce $\mathrm{Fe}_{3} \mathrm{O}_{4}$ nanoparticle. The prepared magnetite was stabilized with cross-linked polymer based on 2-acrylamido-2-methylpropane sulfonic acid (AMPS to prepare novel core-shell nanogel. In this respect, $\mathrm{Fe}_{3} \mathrm{O}_{4} /$ poly (2-acrylamido-2-methylpropane sulfonic acid) (PAMPS) magnetic nanogels with controllable particle size produced via free aqueous polymerization at $65^{\circ} \mathrm{C}$ have been developed for the first time. The polymer was crosslinked in the presence of N,N-methylenebisacrylamide (MBA) as a crosslinker and potassium peroxydisulfate (KPS) as redox initiator system. The structure and morphology of the magnetic nanogel were characterized by Fourier transform infrared spectroscopy (FTIR) and transmission and scanning electron microscopy (TEM and SEM). The effectiveness of the synthesized compounds as corrosion inhibitors for carbon steel in $1 \mathrm{M} \mathrm{HCl}$ was investigated by various electrochemical techniques such as potentiodynamic polarization and electrochemical impedance spectroscopy (EIS). The results showed enhancement in inhibition efficiencies with increasing the inhibitor concentrations. The results showed that the nanogel particles act as mixed inhibitors. EIS data revealed that $R_{\mathrm{ct}}$ increases with increasing inhibitor concentration.
\end{abstract}

\section{Introduction}

Corrosion occurs as a result of the formation of a galvanic cell; the anode reaction of this cell is usually metal dissolution and the cathode reaction can be $\mathrm{H}_{2}$ evolution or $\mathrm{O}_{2}$ reduction in acidic and alkaline media, respectively. Cathodic and anodic reactions are heterogeneous reactions involving two steps, a charge transfer step and a mass transfer step. Sometimes the mass transfer step is slower than the charge transfer step and then the rate of corrosion is determined by the diffusion step. The rate of diffusion is governed by the prevailing hydrodynamic conditions. Diffusion-controlled corrosion in pipelines is favored by turbulence since turbulence enhances the rate of mass transfer by thinning the diffusion layer across which the corrosive species, for example, oxygen, and corrosion products diffuse. Mechanistic information on corrosion and the clarification of interactions between inhibitor molecules and metal surfaces have gained considerable attention because of their great potential in corrosion inhibition of metals and alloys [1-5].

Magnetic nanogels, a class of inorganic/polymer coreshell composites with nanoscaled dimension, comprise a core of magnetically susceptive nanoparticle and a shell of crosslinked polymer network. At this point, the magnetic nanogels can be incorporated into the class of mesoporous materials. The polymer network endows the magnetic nanogels with 
excellent swollen capacity, hydrophilicity, and functionalized surface. To date, magnetic nanogels with different functional groups $[6,7]$ had been prepared by photochemical in situ polymerization, based on the investigation of the photopolymerization process of vinyl monomers in several solvents $[8,9]$.

Magnetic nanoparticles have proved to be useful for a number of biomedical applications due to their inherent ultrafine size, superparamagnetic properties, and biocompatibility [10]. The applicability of iron oxide nanoparticles depends upon nanoparticles size, functionality, stability, dispensability, and interfacial surfaces [11-14].

Superparamagnetic iron oxides have great potential for various biomedical applications as targeted drug delivery, magnetic resonance imaging, biological separation contrast enhancement, biosensors, hyperthermia, catalysis, and diagnostic medical devices [15-17]. Modified magnetic nanoparticles have gained considerable attention because of their great potential in biomedical applications, such as enzyme immobilization and protein $[18,19]$. Magnetic nanogels of common interest are ferromagnetic magnetite $\left(\mathrm{Fe}_{3} \mathrm{O}_{4}\right)$ coated with cross-linked polymer nanogel, which possesses strong magnetic property and superparamagnetic behavior. It is characterized by relatively low toxicity to the human body when encapsulated in the protective polymer shell, which is cross-linked polymer hydrogels. It prevents the $\mathrm{Fe}_{3} \mathrm{O}_{4}$ core from oxidation and aggregation. Magnetic nanogels (hydrogel shell) with good hydrophilicity and biocompatibility can be desirable for biomedical applications, such as drug delivery systems. Several methods have been developed to prepare magnetic micro- and nanogels, such as inverse microemulsion polymerization and emulsion polymerization [20-22]. With the conventional methods, however, it is not easy to obtain magnetic nanogels with controllable particle size below $200 \mathrm{~nm}$, which are desirable for several applications [23]. It was expected that the high viscous polymers which were used as drag-reducing polymers declined the rate of corrosion owing to the damping effect exercised by the polymer molecules on the turbulent eddies of the hydrodynamic boundary layer. Sedahmed et al. [24] reported a $40 \%$ decrease in the rate of anodic dissolution of copper in $\mathrm{H}_{3} \mathrm{PO}_{4}$ containing drag-reducing polyethylene oxide polymer. It was previously reported that [25] magnetite nanogel which was prepared by coprecipitation method of $\mathrm{Fe}(\mathrm{III})$ and $\mathrm{Fe}$ (II) salts in the presence of ammonia showed good corrosion inhibition efficiency as protective films for carbon steel alloys. In the present work, the effect of nanogel polymer on the rate of corrosion of carbon steel pipe using aqueous $\mathrm{HCl}$ solution was studied. The objective of the present work was to test the possibility of using cross-linked nanoparticles as corrosion inhibitors in pipelines through which fluids are flowing under turbulent flow conditions. In this work, we propose an alternative approach to synthesize polyacrylamide (PAM) superparamagnetic nanogels based on 2-acrylamido-2-methylpropane sulfonic acid (AMPS) via solution polymerization at room temperatures in an initiator free aqueous system. Sizes of the nanogel particles can be controllable from 10 to $80 \mathrm{~nm}$.

\section{Experimental}

2.1. Materials. Anhydrous ferric chloride, potassium iodide, and ammonium hydroxide (25\%) aqueous solution were used as reagents for preparation of magnetite and were purchased from Aldrich Chemicals Co. Oleic. 2-Acrylamido2-methylpropane sulfonic acid (AMPS) and N,N-methylene bisacrylamide (MBA) were used to prepare cross-linked polymer delivered from Merck and used to prepare nanogel.

2.2. Preparation of $\mathrm{Fe}_{3} \mathrm{O}_{4} / \mathrm{P}$ (AMPS) Nanogels [26]. Anhydrous $\mathrm{FeCl}_{3}(40 \mathrm{~g})$ was dissolved in $300 \mathrm{~mL}$ of distilled water to prepare an aqueous solution A. Furthermore, $13.2 \mathrm{~g}$ $(0.08 \mathrm{~mol})$ of potassium iodide was dissolved in $50 \mathrm{~mL}$ of distilled water to prepare an aqueous solution $\mathrm{B}$. The aqueous solutions $\mathrm{A}$ and $\mathrm{B}$ were then mixed together at room temperature and stirred and allowed to reach equilibrium for one hour while bubbling with pure $\mathrm{N}_{2}$ to keep oxygen free throughout the preparation procedure. A precipitate was filtered out, washed with distilled water, dried at vacuum at $30^{\circ} \mathrm{C}$, and weighed to determine the reaction yield $(95 \%$ yield). AMPS ( $2 \mathrm{~g}), \mathrm{MBA}(0.06 \mathrm{~g} 3 \mathrm{~mol} \%$ with respect to total monomer amount), and $0.01 \mathrm{~g}$ of potassium persulfate were dissolved in the filtrate (including washings) under nitrogen atmosphere and then heated at 65 to $70^{\circ} \mathrm{C}$ for $2 \mathrm{hrs.} 200 \mathrm{~mL}$ of $25 \%$ ammonia solution or $2 \mathrm{M} \mathrm{NaOH}$ was added dropwise with stirring while bubbling with pure $\mathrm{N}_{2}$ to keep oxygen free throughout the preparation procedure. A black suspension was formed upon the addition of $\mathrm{NH}_{4} \mathrm{OH}$ and the suspension was heated to $90^{\circ} \mathrm{C}$ for $30 \mathrm{~min}$. After cooling the mixture to ambient temperature, the suspended magnetite was flocculated by addition of acetone $(200 \mathrm{~mL})$. After separation of the magnetite using a magnet and decanting the mixed solvent, the solid was washed with warm ethanol and acetone.

2.3. Characterization. FTIR spectra were analyzed with a Nicolet FTIR spectrophotometer using $\mathrm{KBr}$ in a wavenumber range of $4000-500 \mathrm{~cm}^{-1}$ with a resolution accuracy of $4 \mathrm{~cm}^{-1}$. All samples were ground and mixed with $\mathrm{KBr}$ and then pressed to form pellets. High resolution transmission electron microscopy (HR-TEM) images for the prepared nanoparticles were recorded using (JEM-2100F, JEOL, Japan) an acceleration voltage of $120 \mathrm{kV}$. The specimens for TEM observation were prepared by the following procedure. The sample was ultrasonically dispersed in ethanol for $5 \mathrm{~min}$, and then a drop of sample suspension was dropped onto a carboncoated copper grid, which was left to stand for $10 \mathrm{~min}$ and transferred into the microscope.

2.4. Electrochemical Measurement. Electrochemical tests were performed in a glass cell with a 3-electrode assembly as follows: working electrode, reference electrode (saturated calomel electrode), and platinum sheet as counter electrode. These tests were carried out with a Solartron 1470E system (potentiostat/galvanostat) and along with Solartron 1455A as frequency response analyzer. The potentiodynamic polarization curves were recorded by applying a $5 \mathrm{mV} \mathrm{s}^{-1}$ scanning rate and electrochemical impedance spectra were 


$$
3 \mathrm{Fe}^{3+}+\mathrm{I}^{-} \rightarrow 2 \mathrm{Fe}^{3+}+\mathrm{Fe}^{2+}+1 / 2 \mathrm{I}^{-}
$$

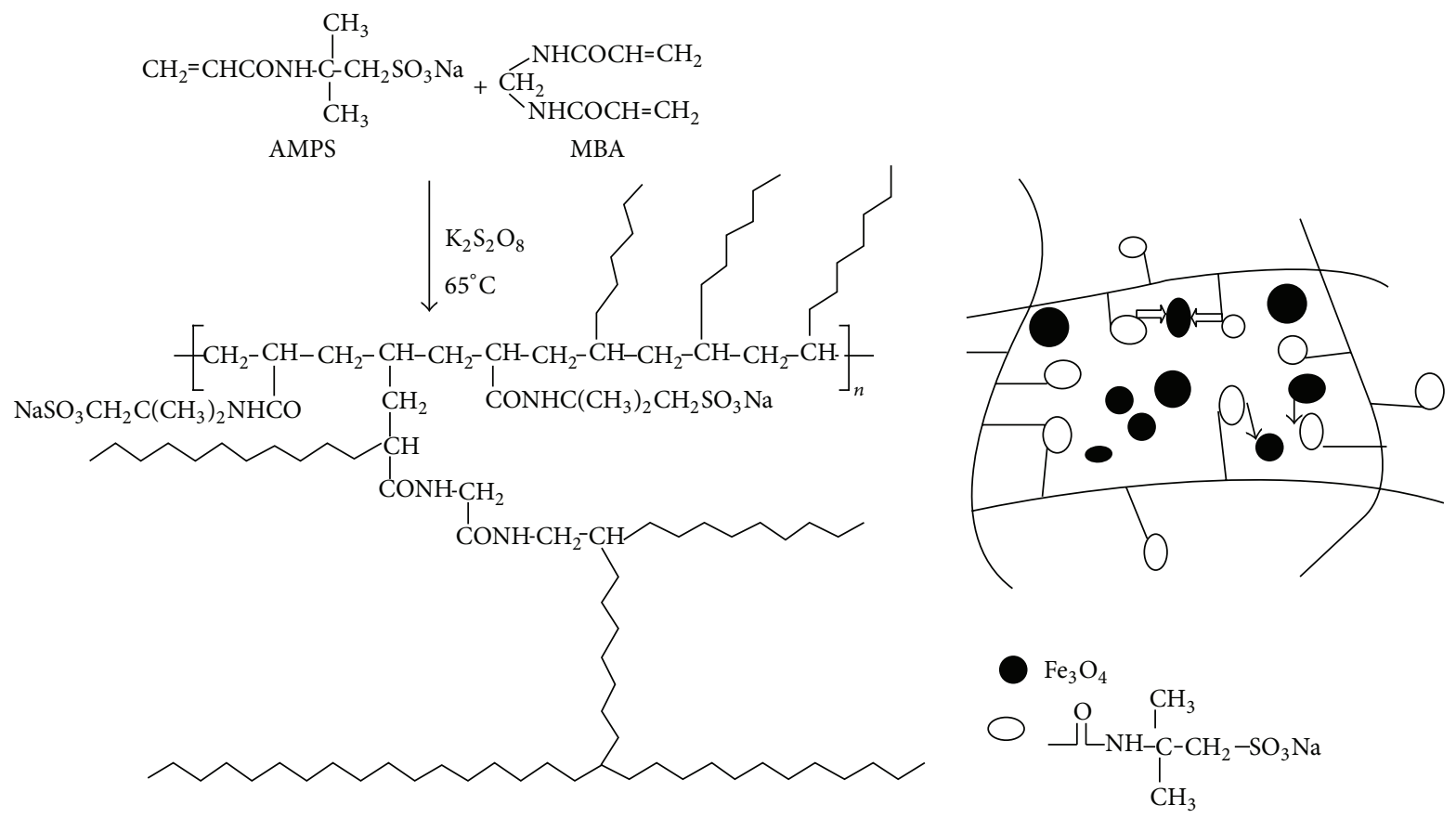

(b)

Scheme 1: Preparation of (a) magnetite and (b) $\mathrm{Fe}_{3} \mathrm{O}_{4} / \mathrm{P}$ (AMPS) nanogel.

performed in the $10^{4}-10^{-2} \mathrm{~Hz}$ frequency range. Multistate software was used to run the tests and collect and evaluate the experimental data. The impedance data were analyzed and fitted with the simulation ZView 3.3c, equivalent circuit software.

\section{Results and Discussion}

The effect of hydrochloric acid $(\mathrm{HCl})$ on the magnetite was previously studied [27-29]. The dissolution of synthetic magnetite, maghemite, hematite, goethite, lepidocrocite, and akaganeite was faster even in $0.5 \mathrm{M} \mathrm{HCI}$ than in $\mathrm{HCIO}_{4}$ [29]. It was suggested that the formation of $\mathrm{Fe}-\mathrm{Cl}$ surface complexes assists dissolution. Extant experimental data indicate that the solubility is controlled via the equilibrium [30]

$$
\mathrm{Fe}_{3} \mathrm{O}_{4}+6 \mathrm{HCl}+\mathrm{H}_{2} \longrightarrow 3 \mathrm{FeCl}_{2}+4 \mathrm{H}_{2} \mathrm{O}
$$

The objective of this work has been achieved by a method for preparing coated magnetite nanoparticles as illustrated in the experimental section. The magnetite formed according to proposed mechanism as represented in Scheme 1. In this respect superparamagnetic magnetite $\mathrm{Fe}_{3} \mathrm{O}_{4}$ nanoparticles were prepared by different modified methods according to the following chemical equation:

$$
3 \mathrm{Fe}^{3+}+\mathrm{I}^{-} \longrightarrow 2 \mathrm{Fe}^{3+}+\mathrm{Fe}^{2+}+\frac{1}{2} \mathrm{I}^{-}
$$

The magnetite was linked with amide and sulfonate groups of both AMPS and MBA through hydrogen bond as discussed in previous work $[25,26]$. In this respect, as represented in Scheme 1, $\mathrm{Fe}_{3} \mathrm{O}_{4}$ nanoparticles were prepared by partial reduction of ferric ion by using potassium iodide as a moderate reducing agent and succeeding coprecipitation by diluted ammonium hydroxide. It was proposed that AMPS, monomers, and MBA cross-linker were adsorbed on the modified iron oxide particle through chelation between $\mathrm{Fe}_{3} \mathrm{O}_{4}$ and the sulfur and oxygen and nitrogen atoms of monomers. The cross-linked polymers were polymerized onto the surface of the magnetic nanoparticles by a free radical polymerization in the presence of MBA cross-linker. The monomers and cross-linker were prone to be adsorbed on $\mathrm{Fe}_{3} \mathrm{O}_{4}$ surface primarily. Additionally, the molar extinction coefficient of nanosized $\mathrm{Fe}_{3} \mathrm{O}_{4}$ at $65^{\circ} \mathrm{C}$ was much larger than that of AMPS or MBA molecules in solution, so when the system was thermally heated at $65^{\circ} \mathrm{C}, \mathrm{Fe}_{3} \mathrm{O}_{4}$ nanoparticles were thought to absorb the vinyl monomers and MBA molecules on the surface of $\mathrm{Fe}_{3} \mathrm{O}_{4}$ nanoparticles which were activated and polymerized $[25,26]$. It was expected 


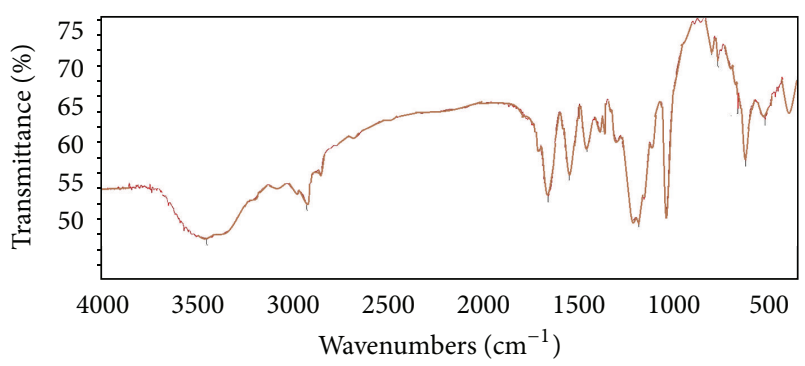

Figure 1: FTIR spectrum of $\mathrm{Fe}_{3} \mathrm{O}_{4} / \mathrm{p}$ (AMPS) nanogel.

that AMPS functionalized magnetic nanogels synthesized via thermal polymerization would be a core shell structure, where nanosized $\mathrm{Fe}_{3} \mathrm{O}_{4}$ was the core and PAMPS-Na, formed with $2 \mathrm{M} \mathrm{NaOH}$, was aminofunctionalized hydrophilic gel shell.

3.1. Chemical Structure and Morphology of $\mathrm{Fe}_{3} \mathrm{O}_{4} / \mathrm{P}$ (AMPS) Nanogels. FTIR spectrum of $\mathrm{Fe}_{3} \mathrm{O}_{4} / \mathrm{p}$ (AMPS) nanoparticles was represented in Figure 1. The IR spectrum clearly reveals the presence of strong IR absorption bands at between 400 and $630 \mathrm{~cm}^{-1}$ which are the characteristic absorption peaks of $\mathrm{Fe}-\mathrm{O}$ vibration related to $\mathrm{Fe}_{3} \mathrm{O}_{4}$. The bands between 2800 and $3000 \mathrm{~cm}^{-1}$ shown in Figure 1 were referred to the vibrations of $-\mathrm{CH}_{3},-\mathrm{CH}$, and $-\mathrm{CH}_{2}$, indicating the polymerization of AMPS and MBA as illustrated in Scheme 1. The characteristic absorption band of AMPS units is shown at $1040 \mathrm{~cm}^{-1}$ due to $\mathrm{SO}_{3}$ group. The disappearance of bands at 3050,1600 , and $950 \mathrm{~cm}^{-1}$ which is attributed to $=\mathrm{CH}$ stretching, $\mathrm{C}=\mathrm{C}$ stretching, and $=\mathrm{CH}$ (out-of-plan bending), respectively, refers to the complete polymerization of monomers and MBA cross-linker. The bands of 1680 , 1590 , and $1384 \mathrm{~cm}^{-1}$, were assigned to CONH stretching, $\mathrm{NH}$ bending, and $\mathrm{C}-\mathrm{N}$ stretching vibration, respectively that indicated the formation of cross-linked PAMPS-Na (Figure 1).

Transmission electron microscopy (TEM) was used to measure the morphology and particle size of magnetic nanoparticles. Figures 2(a) and 2(b) illustrate the morphology of the prepared magnetite in the presence and absence of AMPS nanogel. Magnetite nanoparticles prepared in the absence of AMPS nanogel, as shown in Figure 2(a), have more distinct morphology with less aggregation. This might be attributed to the fact that magnetite nanoparticles prepared have quite a number of hydroxyl groups on the surface of precipitates from contacting with the aqueous phase. The negative charges on hydroxyl group offer some stability to the prepared nanoparticles during the aging period and delay the aggregation process. TEM of this method reveals formation of monodisperse $\mathrm{Fe}_{3} \mathrm{O}_{4}$ nanoparticles that have a narrow particle size distribution with the mean size of $4-8 \mathrm{~nm}$. TEM image of coated $\mathrm{Fe}_{3} \mathrm{O}_{4} / \mathrm{p}$ (AMPS) was illustrated in Figure 2(b). The TEM images clearly reveal that the nanoparticles are well-shaped spheres with smooth surfaces, with the $\mathrm{Fe}_{3} \mathrm{O}_{4}$ being visible as dark spots inside the magnetic polymer particles. From the figure, it is noticed that all particles joined
TABLE 1: Inhibition efficiency values for carbon steel in $1 \mathrm{M} \mathrm{HCl}$ with different concentrations of AMPS calculated by polarization method.

\begin{tabular}{lccccc}
\hline $\begin{array}{l}\text { Inhibitor } \\
\begin{array}{l}\text { concentration } \\
(\mathrm{ppm})\end{array}\end{array}$ & $B_{a}(\mathrm{mV})$ & $B_{c}(\mathrm{mV})$ & $E_{\text {corr }}(\mathrm{V})$ & $I_{\text {corr }}\left(\mathrm{A} / \mathrm{cm}^{2}\right)$ & $\% \mathrm{IE}$ \\
\hline 50 & 552.39 & 317.53 & -0.572 & $1.89 \times 10^{-5}$ & 59.73 \\
100 & 206.61 & 202.47 & -0.580 & $1.16 \times 10^{-5}$ & 80.19 \\
250 & 241.06 & 174.01 & -0.566 & $0.81 \times 10^{-5}$ & 90.06 \\
\hline
\end{tabular}

as bi-, tri-, tetra-, or penta- nomial particles and increased the particle diameters to be $20-28 \mathrm{~nm}$. This can be attributed to the link formed between amide and sulfonate groups of AMPS and MBA in the network of nanogel as illustrated in Scheme 1. This link can act as protective layer for magnetite from the surrounding environment such as $1 \mathrm{M} \mathrm{HCl}$ which will be illustrated in the next section.

3.2. Polarization Measurements. Potentiodynamic polarization curves for carbon steel in $1 \mathrm{M}$ hydrochloric acid solution containing different concentrations of AMPS are shown in Figure 3. The intersection of Tafel regions of cathodic and anodic branches gives the corrosion current density $\left(i_{\text {corr }}\right)$. Table 1 shows the dependence of $i_{\text {corr }}$ obtained from Tafel plots for carbon steel electrode in $1 \mathrm{M} \mathrm{HCl}$ solution without and with different concentrations of the investigated AMPS. The $i_{\text {corr }}$ values were used to calculate the inhibition efficiency, IE (\%), using the following equation [31]:

$$
\mathrm{IE}(\%)=i_{\text {corr }}^{\circ}-\frac{i_{\text {corr }}}{i_{\text {corr }}^{\circ}},
$$

where $i_{\text {corr }}^{\circ}$ and $i_{\text {corr }}$ are the corrosion current densities for carbon steel electrode in the uninhibited and inhibited solutions, respectively. It is observed that the current density decreased with increasing concentration of the inhibiting molecules, indicating an inhibiting effect. It is clear from Table 1 that corrosion current density $i_{\text {corr }}^{\circ}$ decreased by addition of AMPS derivatives in $1 \mathrm{M} \mathrm{HCl}$. The obtained inhibition efficiencies given in Table 1 show that cationic derivatives act as effective inhibitors. It can be concluded that the addition of cationic inhibitor decreases the corrosion rate of carbon steel by blocking both cathodic and anodic sites, thus decreasing the available sites for corrosion. From the polarization curves, it was observed that the anodic and cathodic reactions were affected by the AMPS inhibitor, which is considered as a mixed-type inhibitor. Thus, it reduces the anodic dissolution of the carbon steel and also retards the cathodic reactions. It is clear from the polarization curve that the anodic curve displays a passive film formation on the electrode surface in the presence of the inhibitor within the studied potentials. This indicates that nanogel particles act as mixedtype inhibitor with predominant cathodic effectiveness. The cathodic current potential curves (Figure 3) gave rise to parallel lines indicating that the addition of cationic to the $1 \mathrm{M} \mathrm{HCl}$ solution did not modify the hydrogen evolution mechanism and the reduction of hydrogen ions at the carbon 


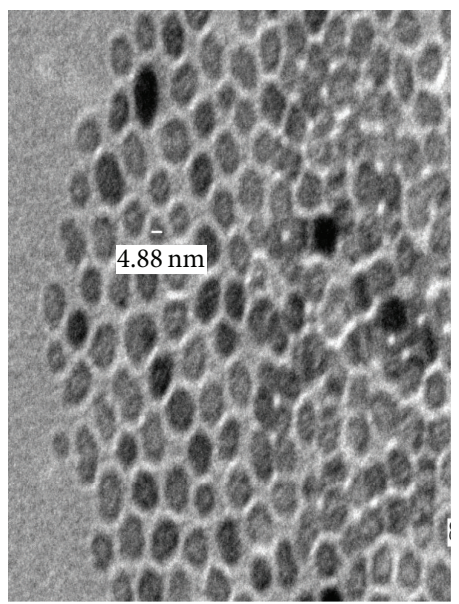

(a)

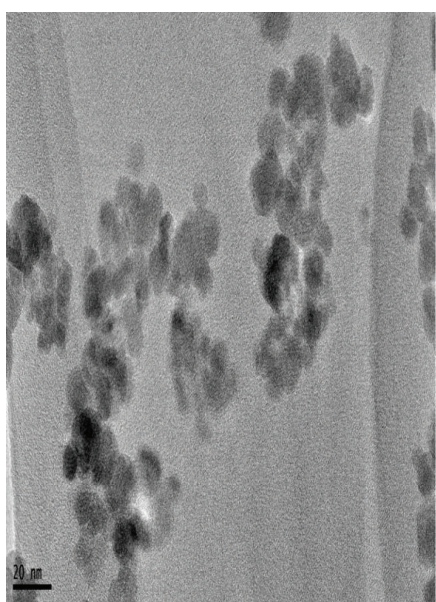

(b)

FIgURE 2: TEM of (a) magnetite and (b) $\mathrm{Fe}_{3} \mathrm{O}_{4} / \mathrm{p}$ (AMPS) nanogel.

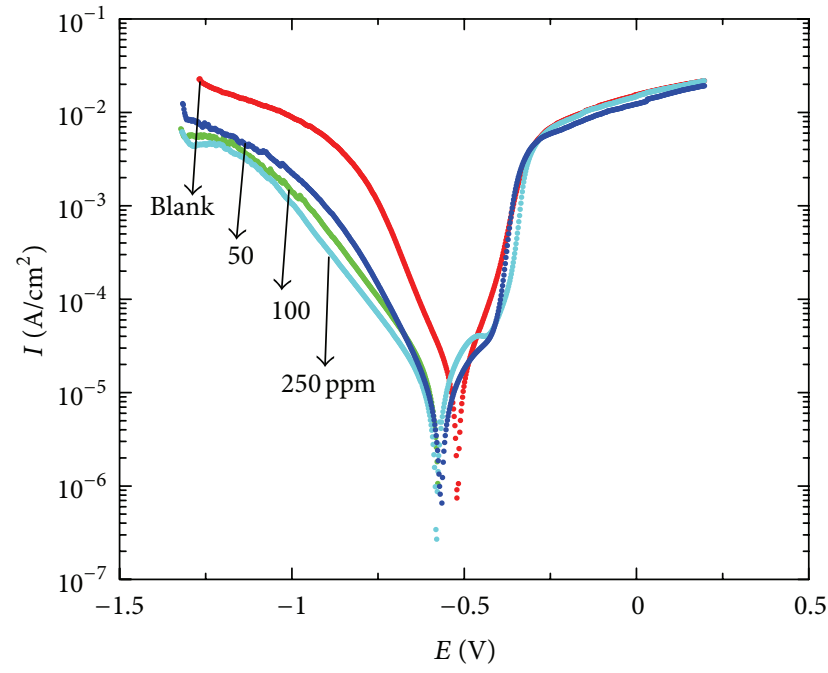

FIgURE 3: Polarization curves for carbon steel in $1 \mathrm{M} \mathrm{HCl}$ solution containing different inhibitor concentrations.

steel surface taken place mainly through a charge transfer mechanism. The anodic polarization curve of carbon steel in $1 \mathrm{M} \mathrm{HCl}$ showed uniform corrosion. The decrease in anodic current densities on increasing the cationic concentration showed that corrosion rate of carbon steel decreased on increasing cationic concentration. It can be concluded that the inhibition process could be related to the reduction of exchange current densities of the cathodic and anodic reactions, which was more sensible for the cathodic reaction. The addition of cationic inhibitor impedes the corrosion via geometric blocking effect, thus blocking the cathodic and the anodic reaction sites on the steel surface. It is clear from the calculated data that nanogel particles inhibit the corrosion of carbon steel to an appreciable extent and the extent of inhibition is dependent on the inhibitor concentration.

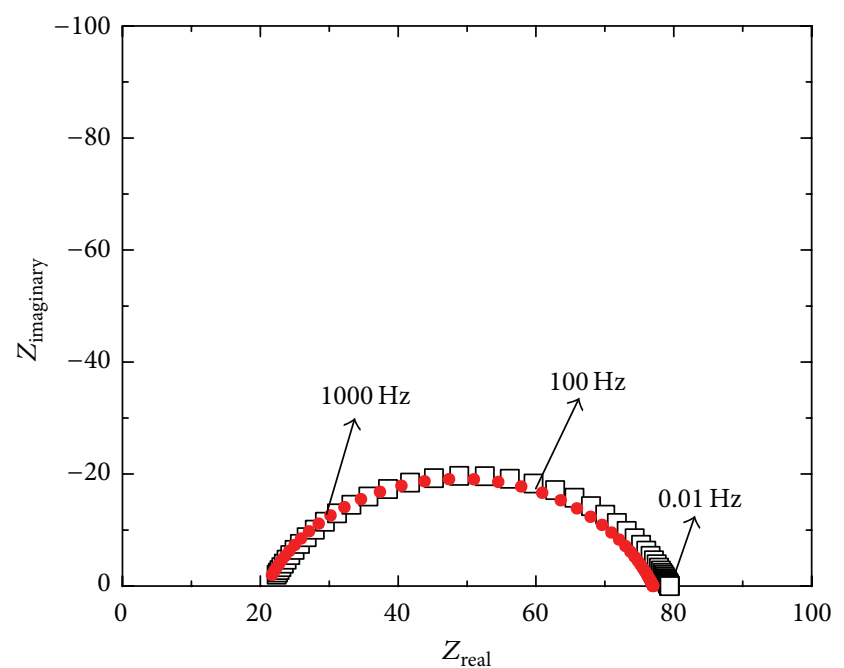

FIgURE 4: Nyquist diagram for carbon steel in $1 \mathrm{M} \mathrm{HCl}$ solution showing experimental and fit data.

3.3. EIS Measurements. The Nyquist plots obtained from the EIS measurements for carbon steel in $1 \mathrm{M} \mathrm{HCl}$ solutions in absence and presence of AMPS inhibitor at different concentrations are shown in Figures 4 and 5, respectively. A single, depressed, and capacitive like semicircle was observed, from high to low frequencies region in the absence of inhibitor and illustrated that the corrosion process was controlled by charge transfer resistance. The appearance of the capacitive semicircle observed in the Nyquist plots is ascribed to the double layer capacitance and the charge transfer resistance of the corrosion process at the electrode surface [32]. Introducing AMPS was observed to increase the semicircle's diameter as shown in Figure 5 indicating inhibition of the corrosion process. Furthermore, the increase in AMPS concentration increased the diameter of the semicircle. The slightly depressed nature of the capacitive semicircles which have the centre below the $x$-axis is the characteristic for solid 


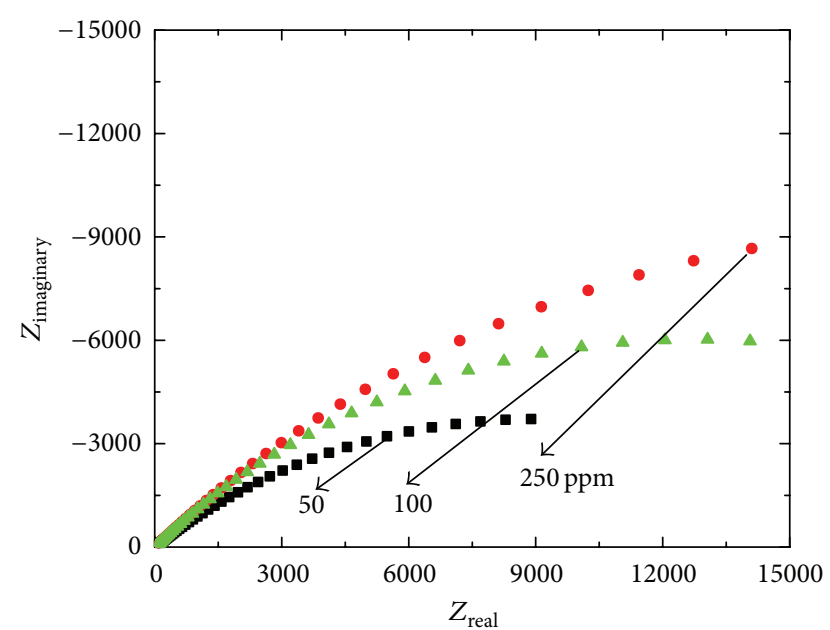

FIgURE 5: Nyquist diagram for carbon steel in $1 \mathrm{M} \mathrm{HCl}$ containing different concentrations of inhibitors.

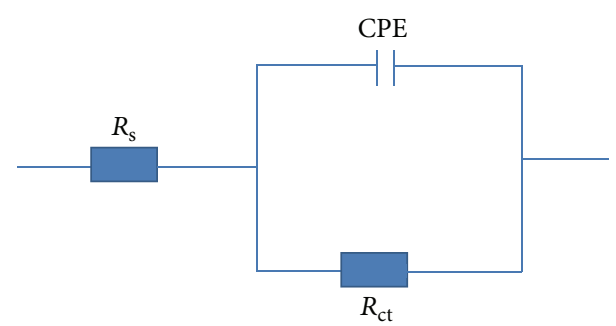

FIGURE 6: Equivalent circuit used for fitting the impedance data in $1 \mathrm{M} \mathrm{HCl}$ solution.

electrodes and has been attributed to the roughness and other inhomogeneities of the electrode [33,34]. As can be seen in Figure 5, in the presence of AMPS the Nyquist plots showed that charge transfer mechanism is no longer the dominant mechanism and it has changed to a diffusion controlled reaction. This may be due to the transport of ions in solution which slowly replaces charge transfer. In other words, the existence of Warburg-type impedance arises indicating that the corrosion process is under diffusion control. Electrical equivalent circuits are generally used to model the electrochemical behaviour and calculate the parameters of interest such as electrolyte resistance $\left(R_{s}\right)$, charge transfer resistance $\left(R_{\mathrm{ct}}\right)$, and double layer capacitance $\left(\mathrm{C}_{\mathrm{dl}}\right)$. In case of presence of a nonideal frequency response, it is commonly accepted to employ distributed circuit elements in an equivalent circuit. The most widely used is a constant phase element (CPE), which has a noninteger power dependence on the frequency. The impedance of a CPE is described by the expression

$$
Z_{\mathrm{CPE}}=Y^{-1}(i \omega)^{-n},
$$

where $Y$ is the $\mathrm{CPE}$ constant proportional to the capacitance of the corroding system $\left(\mathrm{C}_{\mathrm{dl}}\right), i$ is $\sqrt{ }-1$, and $\omega$ is $2^{\Pi} f$, where $f$ is the frequency and $n$ has the meaning of a phase shift. A CPE is often used in a model in place of a capacitor to compensate for nonhomogeneity in the system to take into account irregularities arising from surface roughness

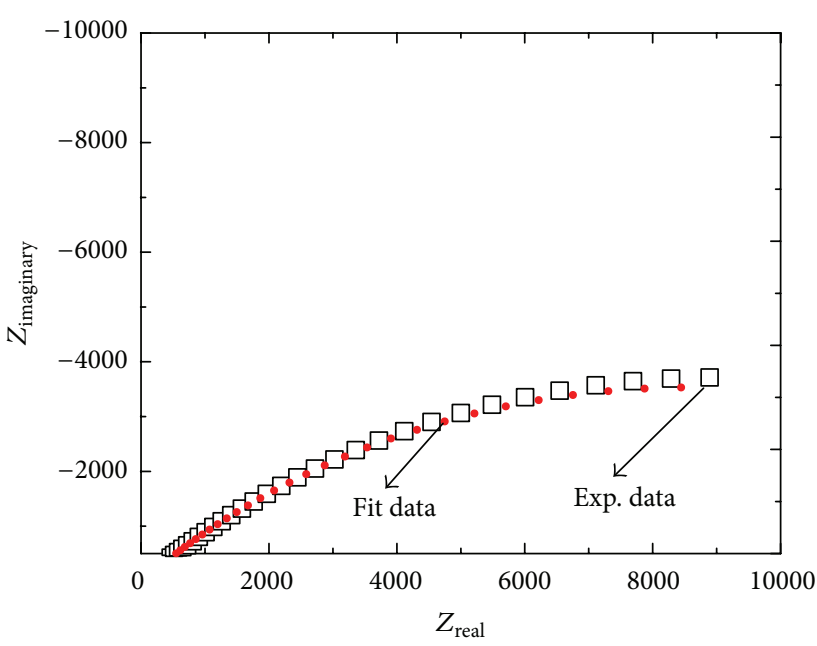

FIgURE 7: Nyquist diagram for carbon steel in $1 \mathrm{M} \mathrm{HCl}$ containing $50 \mathrm{ppm}$ concentration of inhibitor showing experimental and fitting data.

or from other sources such as double layer capacitance or charge transfer rate. The constant phase element represents different electrical elements depending on the value of the exponent $n$. For an ideal capacitor $Y$ is $1 / \mathrm{C}$ and $n=1$, whereas for a nonideal capacitor $n<1$ [35-38]. Hence, the EIS spectra for the presence of IM are described by a simple equivalent circuit as shown in Figure 6. It is necessary to note that a Warburg tail was seen in the Nyquist plots. Thus, $Z_{w}$ component was added to its equivalent circuit, as shown in Figure 3. At low frequency, the capacitive component $\mathrm{C}$ no longer affects the total impedance value and the total impedance, $Z_{t}$, can be presented as follows:

$$
Z_{w}+R_{\mathrm{ct}}+Z_{t}=R_{s} \text {. }
$$

Contribution of the Warburg impedance has also been reported by many researchers [39-44].

The electrochemical interface in the presence of inhibitor was found to be similar to the electrode surface covered with the oxidation product due to corrosion with limited solubility $[45,46]$. It is therefore concluded that the presence of inhibitor introduces the diffusion step in corrosion process and the reaction becomes diffusion controlled. The resistance to the diffusion process at the electrochemical interface increases with an increase in the inhibitor concentration. This in turn inhibits corrosion process. Inhibitors get adsorbed on the electrode surface and thereby produce an extra barrier for diffusion process and this barrier increases with increasing inhibitor concentration. Figure 7 shows the Nyquist diagram for carbon steel in $1 \mathrm{M} \mathrm{HCl}$ containing $50 \mathrm{ppm}$ concentration of inhibitor showing experimental and fitting data. The values of inhibition efficiency (IE\%) were determined from the following equation:

$$
\mathrm{IE} \%=R_{\mathrm{ct}}(\mathrm{inh})-\frac{R_{\mathrm{ct}}(\mathrm{uninh})}{R_{\mathrm{ct}}(\mathrm{inh})} \times 100,
$$

where $R_{\mathrm{ct}}$ (uninh) and $R_{\mathrm{ct}}(\mathrm{inh})$ are the uninhibited and inhibited charge transfer resistance, respectively. The inhibition 


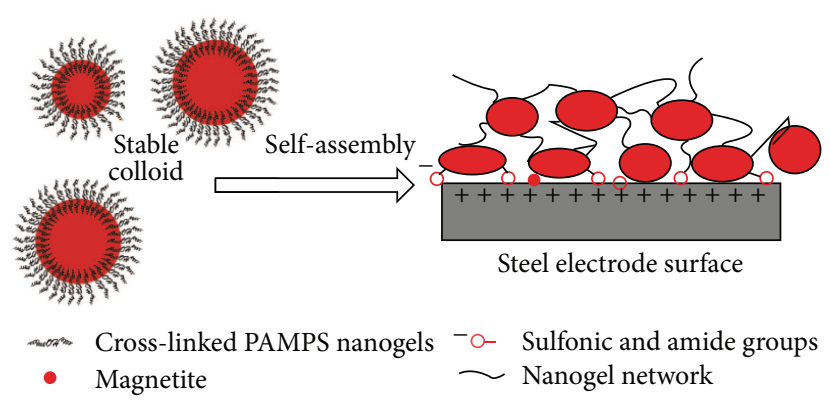

FIGURE 8: Mechanism of corrosion inhibition of $\mathrm{Fe}_{3} \mathrm{O}_{4} / \mathrm{p}$ (AMPS) nanogels on steel surfaces.

TABLE 2: Inhibition efficiency values for carbon steel in $1 \mathrm{M} \mathrm{HCl}$ with different concentrations of AMPS calculated by EIS technique.

\begin{tabular}{lc}
\hline Inhibitor concentration $(\mathrm{ppm})$ & EI \% EIS technique \\
\hline 50 & 96.78 \\
100 & 97.72 \\
100 & 98.18 \\
\hline
\end{tabular}

efficiency is observed to be increased with IM concentration as clear from the data presented in Table 2.

3.4. Mechanism of AMPS Adsorption. The mechanism of corrosion inhibition of $\mathrm{Fe}_{3} \mathrm{O}_{4} / \mathrm{p}$ (AMPS) nanogels can be illustrated in Figure 8. The $\mathrm{Fe}_{3} \mathrm{O}_{4} / \mathrm{p}$ (AMPS) nanogels have the ability to disperse in the aqueous acidic solution due to the presence of $\mathrm{SO}_{3}{ }^{-2}$ group in their structure, which increased their dispersion in the aqueous medium with the formation of monodispersed nanogels. The repulsive forces between sulfonate groups and the capability of amide group to form stable hydrogen bonds suggest the dispersion of nanogels. The $\mathrm{Fe}_{3} \mathrm{O}_{4}$ particles, which possess negative charges, can be deposited on the surface of steel electrode (positive charges), which acts as protective layer and prevents the interaction between $\mathrm{HCl}$ and carbon steel surface [47]. On the other hand, the interaction between steel surface substrate amide and sulfonic groups of the cross-linked $\mathrm{Fe}_{3} \mathrm{O}_{4} / \mathrm{p}$ (AMPS) nanogels reduced both cathodic and anodic corrosion reactions.

\section{Conclusions}

(1) Magnetite nanoparticle was prepared by new method based on reduction of $\mathrm{Fe}$ (III) ions with potassium iodide to produce $\mathrm{Fe}_{3} \mathrm{O}_{4}$ nanoparticle. The prepared magnetite was stabilized with cross-linked polymer based on 2-acrylamido-2-methylpropane sulfonic acid (AMPS to prepare novel core-shell nanogel).

(2) The structure and morphology of the magnetic nanogel was characterized by Fourier transform infrared spectroscopy (FTIR) and transmission and scanning electron microscopy (TEM and SEM).
(3) 1-AMPS derivative inhibited the corrosion of carbon steel in $1 \mathrm{M} \mathrm{HCl}$ solution and the extent of inhibition was concentration dependent and inhibition efficiency increased with increase in concentration of inhibitor.

(4) Polarization results have shown that the AMPS derivatives act as mixed-type inhibitor without modifying the mechanism of hydrogen evolution.

\section{Acknowledgment}

The authors extend their appreciation to the Deanship of Scientific Research at King Saud University for funding this work through research group no. RGP-VPP-235.

\section{References}

[1] J. M. Costa and J. M. Lluch, "The use of quantum mechanics calculations for the study of corrosion inhibitors," Corrosion Science, vol. 24, no. 11-12, pp. 929-933, 1984.

[2] R. Sayós, M. González, and J. M. Costa, “On the use of quantum chemical methods as an additional tool in studying corrosion inhibitor substances," Corrosion Science, vol. 26, no. 11, pp. 927934, 1986.

[3] P. G. Abdul-Ahad and S. H. F. Al-Madfai, "Elucidation of corrosion inhibition mechanism by means of calculated electronic indexes," Corrosion, vol. 45, no. 12, pp. 978-980, 1989.

[4] F. B. Growcock, "Inhibition of steel corrosion in $\mathrm{HCl}$ by derivatives of cinnamaldehyde. Part I. corrosion inhibition model," Corrosion, vol. 45, no. 12, pp. 1003-1007, 1989.

[5] F. B. Growcock, W. W. Frenier, and P. A. Andreozzi, "Inhibition of steel corrosion in $\mathrm{HCl}$ by derivatives of cinnamaldehyde. Part II. structure-activity correlations," Corrosion, vol. 45, no. 12, pp. 1007-1015, 1989.

[6] P. Gong, J. Yu, H. Sun et al., "Preparation and characterization of $\mathrm{OH}$-functionalized magnetic nanogels under UV irradiation," Journal of Applied Polymer Science, vol. 101, no. 3, pp. 1283-1290, 2006.

[7] H. Sun, J. Yu, P. Gong, D. Xu, C. Zhang, and S. Yao, "Novel core-shell magnetic nanogels synthesized in an emulsion-free aqueous system under UV irradiation for targeted radiopharmaceutical applications," Journal of Magnetism and Magnetic Materials, vol. 294, no. 3, pp. 273-280, 2005.

[8] A. J. Hoffman, H. Yee, G. Mills, and M. R. Hoffmann, "Photoinitiated polymerization of methyl methacrylate using Q-sized 
ZnO colloids," Journal of Physical Chemistry, vol. 96, no. 13, pp. 5540-5546, 1992.

[9] A. L. Stroyuk, V. M. Granchak, A. V. Korzhak, and S. Y. Kuchmii, "Photoinitiation of buthylmethacrylate polymerization by colloidal semiconductor nanoparticles," Journal of Photochemistry and Photobiology A, vol. 162, no. 2-3, pp. 339-351, 2004.

[10] L. Ah, E. Salabas, and F. Schuth, "Magnetic nanoparticles: synthesis, protection, functionalization, and application," Angewandte Chemie, vol. 46, no. 8, pp. 1222-1244, 2007.

[11] M. Namdeo, S. Saxena, R. Tankhiwale, M. Bajpai, Y. M. Mohan, and S. K. Bajpai, "Magnetic nanoparticles for drug delivery applications," Journal of Nanoscience and Nanotechnology, vol. 8, no. 7, pp. 3247-3271, 2008.

[12] T. Dey, "Polymer-coated magnetic nanoparticles: surface modification and end-functionalization," Journal of Nanoscience and Nanotechnology, vol. 6, no. 8, pp. 2479-2483, 2006.

[13] A. K. Gupta, R. R. Naregalkar, V. D. Vaidya, and M. Gupta, "Recent advances on surface engineering of magnetic iron oxide nanoparticles and their biomedical applications," Nanomedicine, vol. 2, no. 1, pp. 23-39, 2007.

[14] S. Y. Lee and M. T. Harris, "Surface modification of magnetic nanoparticles capped by oleic acids: characterization and colloidal stability in polar solvents," Journal of Colloid and Interface Science, vol. 293, no. 2, pp. 401-408, 2006.

[15] J. R. McCarthy and R. Weissleder, "Multifunctional magnetic nanoparticles for targeted imaging and therapy," Advanced Drug Delivery Reviews, vol. 60, no. 11, pp. 1241-1251, 2008.

[16] V. Salgueirino-Maceira and M. A. Correa-Duarte, "Increasing magnetic core-shell structured nanocomposites complexity for biological applications," Advanced Materials, vol. 19, no. 23, pp. 4131-4144, 2007.

[17] O. Veiseh, J. W. Gunn, and M. Zhang, "Design and fabrication of magnetic nanoparticles for targeted drug delivery and imaging," Advanced Drug Delivery Reviews, vol. 62, no. 3, pp. 284-304, 2010.

[18] M. Konerackáa, P. Kopčfdýa, M. Antalíka, M. Timko, C. N. Ramchand, and D. Lobo, "Immobilization of proteins and enzymes to fine magnetic particles," Journal of Magnetism and Magnetic Materials, vol. 201, no. 1-3, pp. 427-430, 1999.

[19] J. Li, X. He, Z. Wu, K. Wang, G. Shen, and R. Yu, "Piezoelectric immunosensor based on magnetic nanoparticles with simple immobilization procedures," Analytica Chimica Acta, vol. 481, no. 2, pp. 191-198, 2003.

[20] H. Sun, J. Yu, P. Gong, D. Xu, C. Zhang, and S. Yao, "Novel core-shell magnetic nanogels synthesized in an emulsion-free aqueous system under UV irradiation for targeted radiopharmaceutical applications," Journal of Magnetism and Magnetic Materials, vol. 294, no. 3, pp. 273-280, 2005.

[21] J. Hong, D. Xu, P. Gong, J. Yu, H. Ma, and S. Yao, "Covalentbonded immobilization of enzyme on hydrophilic polymer covering magnetic nanogels," Microporous and Mesoporous Materials, vol. 109, no. 1-3, pp. 470-477, 2008.

[22] H. Noguchi, N. Yanase, Y. Uchida, and T. Suzuta, "Preparation and characterization by thermal analysis of magnetic latex particles," Journal of Applied Polymer Science, vol. 48, no. 9, pp. 1539-1547, 1993.

[23] S. V. Vinogradov, T. K. Bronich, and A. V. Kabanov, "Nanosized cationic hydrogels for drug delivery: preparation, properties and interactions with cells," Advanced Drug Delivery Reviews, vol. 54, no. 1, pp. 135-147, 2002.
[24] G. H. Sedahmed, B. A. Abd El-Naby, and A. Abdel-Khali, "Corrosion inhibition through decreasing the rate of mass transfer by drag-reducing agents," Corrosion Science, vol. 17, no. 10, pp. 865-869, 1977.

[25] A. M. Atta, O. E. El-Azabawy, H. S. Ismail, and M. A. Hegazy, "Novel dispersed magnetite core-shell nanogel polymers as corrosion inhibitors for carbon steel in acidic medium," Corrosion Science, vol. 53, no. 5, pp. 1680-1689, 2011.

[26] A. M. Atta and A. K. F. Dyab, "Coated magnetite nanoparticles, method for the preparation thereof and their use," European patent field, with application no: EP13167616.5, 2013.

[27] R. Matsuno, K. Yamamoto, H. Otsuka, and A. Takahara, "Polystyrene-and poly(3-vinylpyridine)-grafted magnetite nanoparticles prepared through surface-initiated nitroxidemediated radical polymerization," Macromolecules, vol. 37, no. 6, pp. 2203-2209, 2004.

[28] C. E. Astete, C. S. S. R. Kumar, and C. M. Sabliov, "Size control of poly(d,l-lactide-co-glycolide) and poly(d,l-lactideco-glycolide)-magnetite nanoparticles synthesized by emulsion evaporation technique," Colloids and Surfaces A, vol. 299, no. 13, pp. 209-216, 2007.

[29] P. S. Sidhu, R. J. Gilkes, R. M. Cornell, A. M. Posner, and J. P. Quirk, "Dissolution of iron oxides and oxyhydroxides in hydrochloric and perchloric acids," Clays \& Clay Minerals, vol. 29, no. 4, pp. 269-276, 1981.

[30] I.-M. Chou and H. P. Eugster, "Solubility of magnetite in supercritical chloride solutions," American Journal of Science, vol. 277, pp. 1296-1314, 1977.

[31] F. Z. Bouanis, F. Bentiss, M. Traisnel, and C. Jama, "Enhanced corrosion resistance properties of radiofrequency cold plasma nitrided carbon steel: gravimetric and electrochemical results," Electrochimica Acta, vol. 54, no. 8, pp. 2371-2378, 2009.

[32] P. C. Okafor, C. B. Liu, X. Liu, and Y. G. Zheng, "Inhibition of $\mathrm{CO}_{2}$ corrosion of $\mathrm{N} 80$ carbon steel by carboxylic quaternary imidazoline and halide ions additives," Journal of Applied Electrochemistry, vol. 39, no. 12, pp. 2535-2543, 2009.

[33] P. C. Okafor and Y. G. Zheng, "Synergistic inhibition behaviour of methylbenzyl quaternary imidazoline derivative and iodide ions on mild steel in $\mathrm{H}_{2} \mathrm{SO}_{4}$ solutions," Corrosion Science Journal, vol. 51, no. 4, pp. 850-859, 2009.

[34] Y.-S. Choi, S. Nesic, and S. Ling, "Effect of $\mathrm{H}_{2} \mathrm{~S}$ on the $\mathrm{CO}_{2}$ corrosion of carbon steel in acidic solutions," Electrochimica Acta, vol. 56, no. 4, pp. 1752-1760, 2011.

[35] K. Bílková and E. Gulbrandsen, "Kinetic and mechanistic study of $\mathrm{CO}_{2}$ corrosion inhibition by cetyl trimethyl ammonium bromide," Electrochimica Acta, vol. 53, no. 16, pp. 5423-5433, 2008.

[36] D. M. Ortega-Toledo, J. G. Gonzalez-Rodriguez, M. Casales, M. A. Neri-Florez, and A. Martinez-Villafaňe, "The $\mathrm{CO}_{2}$ corrosion inhibition of a high strength pipeline steel by hydroxyethyl imidazoline," Materials Chemistry and Physics, vol. 122, no. 23, pp. 485-490, 2010.

[37] J. G. Gonzalez-Rodriguez, T. Zeferino-Rodriguez, D. M. Ortega et al., "Effect of microestructure on the $\mathrm{CO}_{2}$ corrosion inhibition by carboxyamidoimidazolines on a pipeline steel," International Journal of Electrochemical Science, vol. 2, pp. 883-896, 2007.

[38] E. F. Diaz, J. G. Gonzalez-Rodriguez, A. Martinez-Villafaňe, and C. Gaona-Tiburcio, " $\mathrm{H}_{2} \mathrm{~S}$ corrosion inhibition of an ultra high strength pipeline by carboxyethyl-imidazoline," Journal of Applied Electrochemistry, vol. 40, no. 9, pp. 1633-1640, 2010. 
[39] M. A. Quraishi, I. H. Farooqi, and P. A. Saini, “Technical note inhibition of dezincification of 70-30 brass by aminoalkyl mercaptotriazoles," British Corrosion Journal, vol. 35, no. 1, pp. 78-80, 2000.

[40] Y. Chen, T. Hong, M. Gopal, and W. P. Jepson, "EIS studies of a corrosion inhibitor behavior under multiphase flow conditions," Corrosion Science, vol. 42, no. 6, pp. 979-990, 2000.

[41] G. A. Moraga, G. G. Silva, T. Matencio, and R. M. Paniago, "Poly(2,5-dimethoxy aniline)/fluoropolymer blend coatings to corrosion inhibition on stainless steel," Synthetic Metals, vol. 156, no. 16-17, pp. 1036-1042, 2006.

[42] G. Bellanger, "Inhibition of localized corrosion for stainless steels in low-level radioactive water containing chloride," Corrosion Science, vol. 48, no. 6, pp. 1379-1403, 2006.

[43] E. M. Sherif and S.-M. Park, "Inhibition of copper corrosion in acidic pickling solutions by N-phenyl-1,4-phenylenediamine," Electrochimica Acta, vol. 51, no. 22, pp. 4665-4673, 2006.

[44] A. K. Satpati and P. V. Ravindran, "Electrochemical study of the inhibition of corrosion of stainless steel by 1,2,3-benzotriazole in acidic media," Materials Chemistry and Physics, vol. 109, no. 2-3, pp. 352-359, 2008.

[45] ASTM, Designation, G-106, 427, 1994.

[46] M. Saremi, C. Dehghanian, and M. M. Sabet, "The effect of molybdate concentration and hydrodynamic effect on mild steel corrosion inhibition in simulated cooling water," Corrosion Science, vol. 48, no. 6, pp. 1404-1412, 2006.

[47] M. Lattuada and T. A. Hatton, "Functionalization of monodisperse magnetic nanoparticles," Langmuir, vol. 23, no. 4, pp. 2158-2168, 2007. 

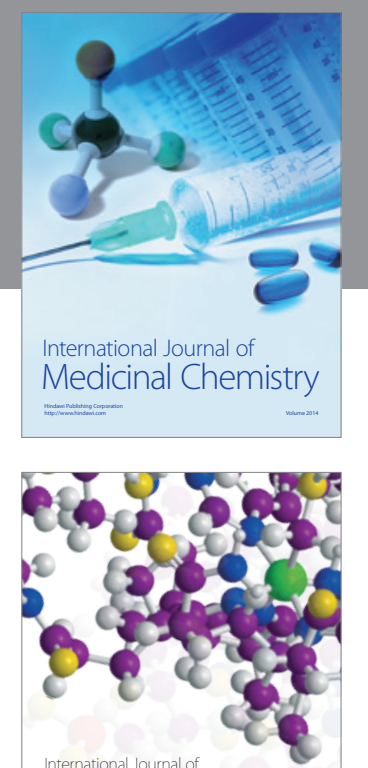

\section{Carbohydrate} Chemistry

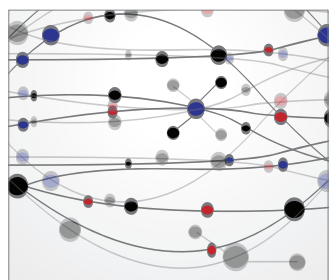

The Scientific World Journal
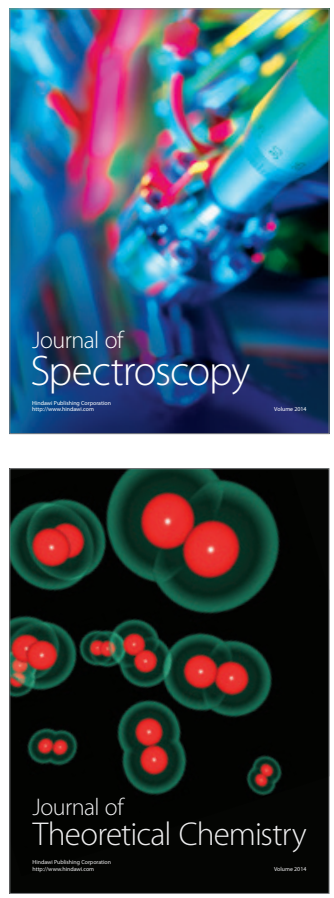
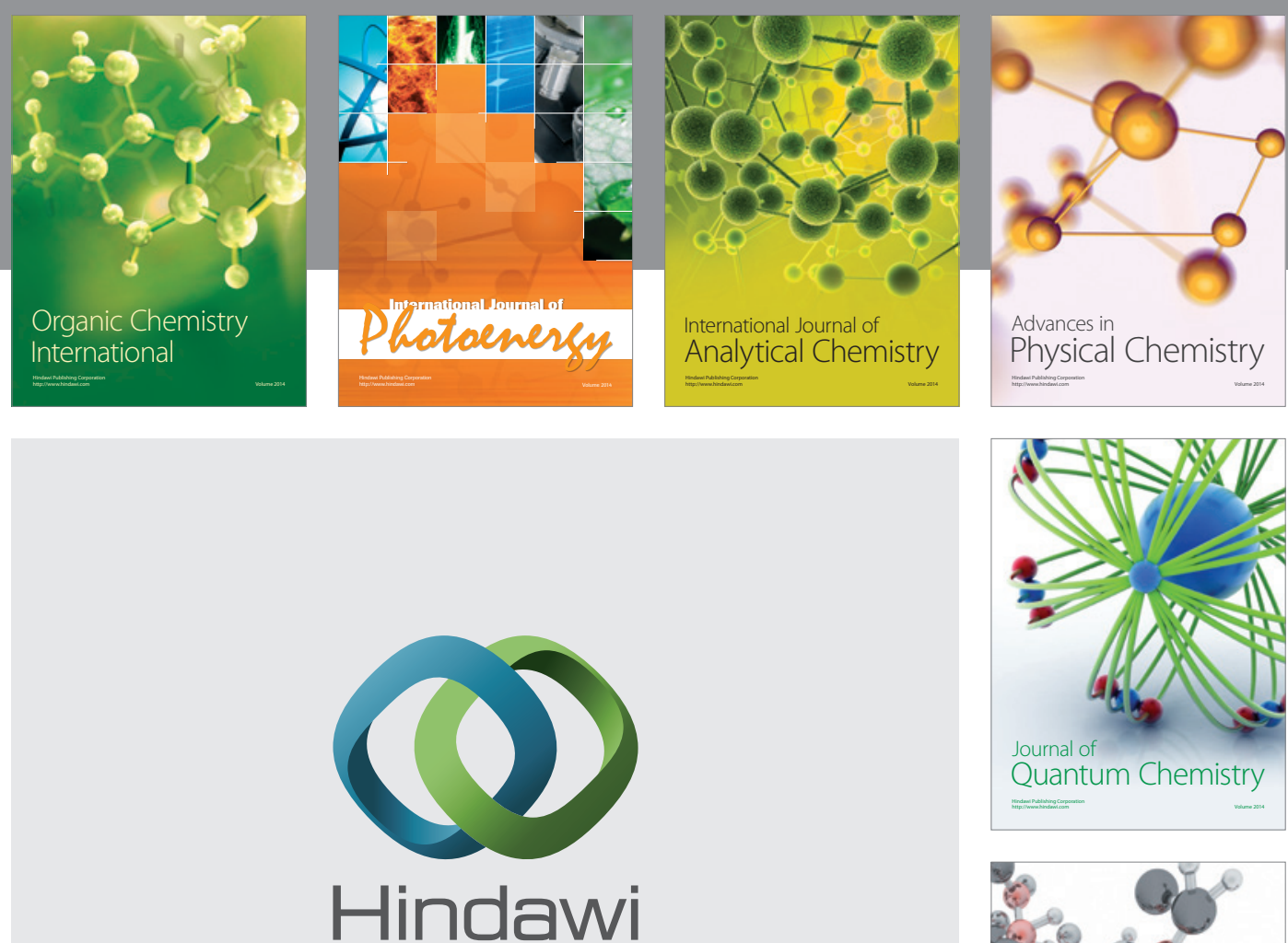

Submit your manuscripts at

http://www.hindawi.com

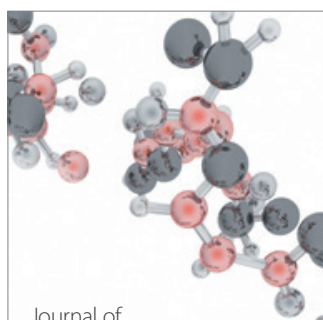

Analytical Methods

in Chemistry

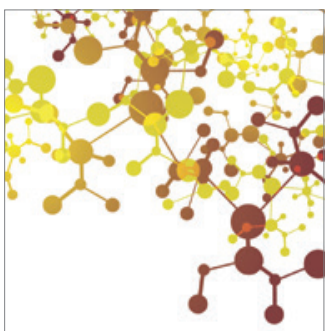

Journal of

Applied Chemistry

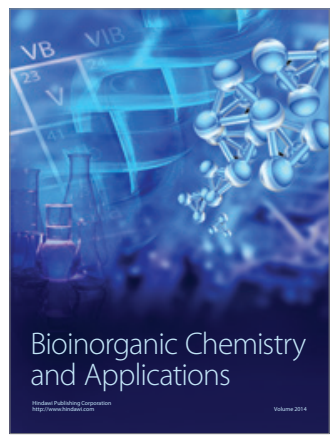

Inorganic Chemistry
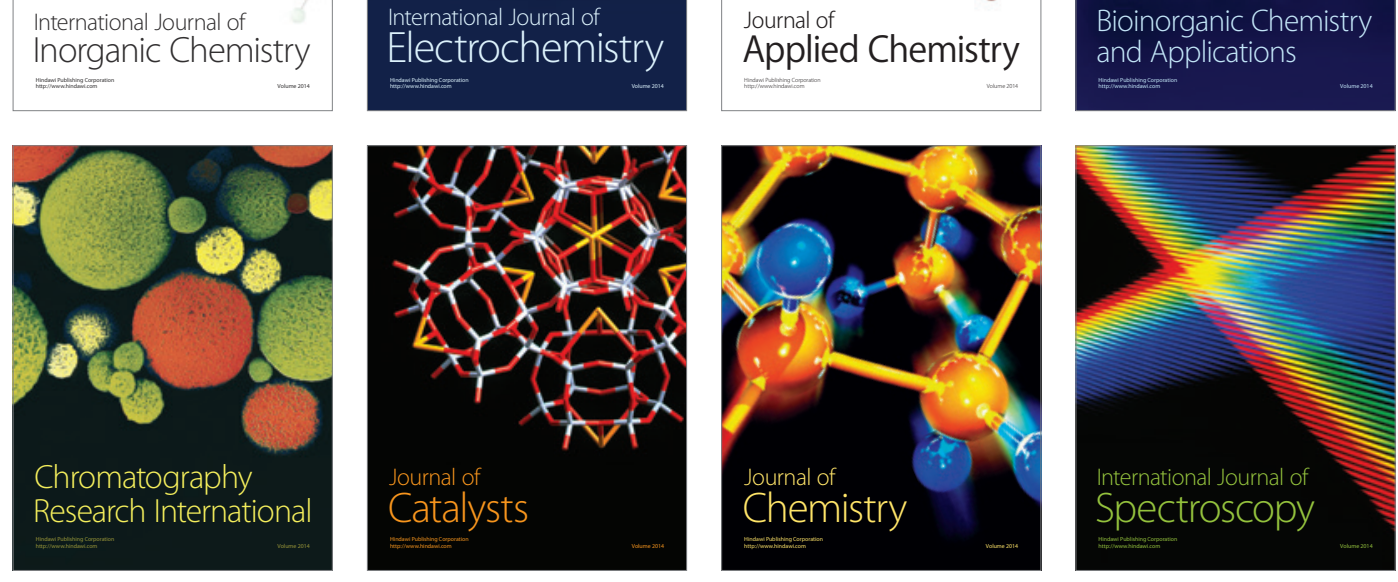